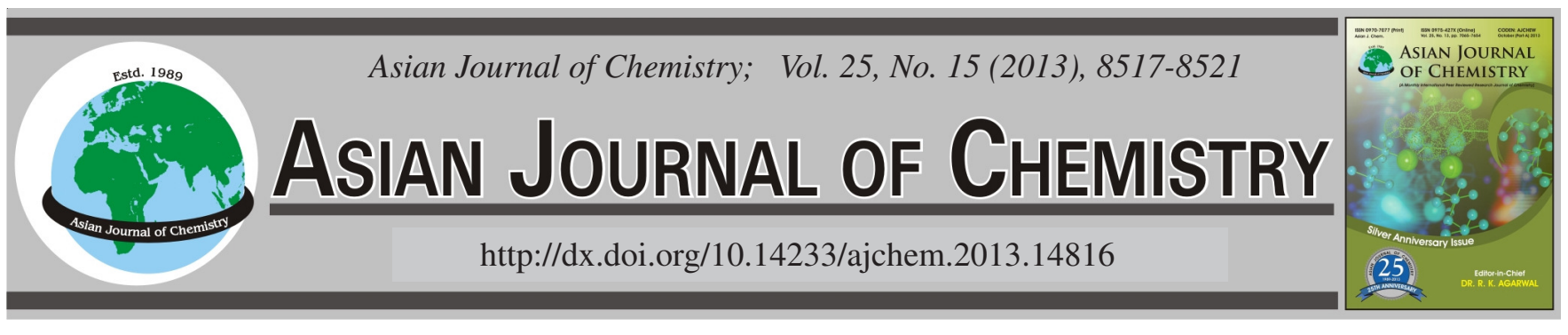

\title{
Screening the Antiangiogenic Constituents from Salvia przewalskii Maxim and Quantitative Analysis of Them
}

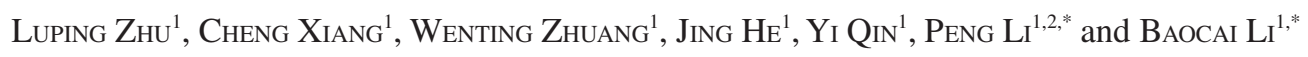

${ }^{1}$ Faculty of Life Science and Technology, Kunming University of Science and Technology, Kunming 650500, P.R. China

${ }^{2}$ State Key Laboratory of Quality Research in Chinese Medicine, Institute of Chinese Medical Sciences, University of Macau, Macau 000856 , P.R. China

*Corresponding authors: Tel: +86 15912531421; E-mail: zhuluping86@163.com; baocaili@hotmail.com

\begin{abstract}
The aim of the present study was to isolate the anti-angiogenic compounds from Salvia przewalskii Maxim rapidly and quantitative analysis of them. The activity-oriented separation method was used to isolate and the anti-angiogenic activity was evaluated by using the chicken chorioallantoic membrane (CAM) neovascularisation model and RP-HPLC was adopted to quantitative analysis. The results showed that the acetone extract from S. przewalskii was isolated into four fractions (Fr.1, Fr.2, Fr.3, Fr.4) with different polarity, among them Fr.3 could inhibit angiogenesis significantly. In order to isolate the major anti-angiogenic compounds, przewaquinone A and przewaquinone B were isolated and identified from Fr.3 and showed potential antiangiogenic activity and the contents of przewaquinone A and B in Fr.3 were 38.16 and $9.51 \%$, respectively. These findings suggested that przewaquinone A and B may be promising candidate for angiogenesis inhibitors, the activity combined with the contents of przewaquinone A and B in Fr.3 is the reason why did Fr.3 could inhibit angiogenesis significantly, so we can demonstrate that the relationship between pharmaceutical effect and material foundation is correlative.
\end{abstract}

Key Words: S. przewalskii Maxim, Przewaquinone A, Antiangiogenic activity, Quantitative analysis.

\section{INTRODUCTION}

Salvia przewalskii Maxim (Hong Qin Jiao in Chinese) is a plant of Subgenus Salvia of Salvia of Labiatae. It was widely distributed in the west of China ${ }^{1}$. It has been used as traditional Chinese medicines (TCM) for a long history and have the similar pharmacological activity with another well known Chinese herbal medicine Salvia miltiorrhiza Bunge, such as antibacterial, antiinflammatory and antioxidant activity ${ }^{2}$. In recent years, S. przewalskii was attracting more and more interest from plant chemist and many secondary metabolites of this plant have been isolated, such as tanshinone I, tanshinone IIA, dihydrotanshinone, cryptotanshinone ${ }^{3}$. Apart from tanshinones, also other bioactive compounds, such as triterpenoids (przewanoic acid $\mathrm{A}$ and $\mathrm{B}$, oleanolic and ursolic acids $)^{4}$ and phenolic derivatives (lithospermic acid B esters) ${ }^{5}$, have been isolated from $S$. przewalskii. But there are few reports about its antiangiogenic effect.

Angiogenesis is the growth of neovessels from existing vasculature. Usually, angiogenesis is tightly controlled by a balance of angiogenesis factors and inhibitors, Under physiological conditions, the growth of neovessels is essential for organ growth and repair, which is fundamental to normal wound healing, reproduction and embryonic development ${ }^{6}$. Inversely, under pathological conditions, uncontrolled angiogenesis is a major contributor to a number of diseases, such as solid tumors, tumor metastasis, rheumatoid arthritis and diabetic retinopathy ${ }^{7}$, so antiangiogenesis therapy has become a new strategy for treating tumors ${ }^{8,9}$. As a result, recent investigations have focused on angiogenesis inhibitors from traditional Chinese medicine and some achievements have been obtained. Tanshinone II A and cryptotanshinone, which were the basis chemical compositions of S. przewalskii, showed the antiangiogenic activity ${ }^{10,11}$. From this report we speculate that S. przewalskii may have other chemical compounds could inhibit angiogenesis. Therefore, the study on the anti-angiogenic ingredients from this plant was carried out.

In our study, the anti-angiogenic compounds from $S$. przewalskii was isolated by activity-oriented separation method. Przewaquinone A and B were isolated and identified from active fraction (Fr.3) and both of them have anti-angiogenic activity. Meanwhile, quantitative analysis of them in Fr.3 was investigated, the results showed that przewaquinone A and B are the major ingredients of Fr.3. 


\section{EXPERIMENTAL}

The plant of S. przewalskii was procured from Li jiang, Yunnan Province, China at august, 2010. The plant identification was authenticated based on its specific morphological and histological characteristics by Pr. Guo shimin at Yunnan institute of traditional Chinese medicine. The plant was airdried immediately after collection, a voucher specimen as a whole plant registered and deposited at the Faculty of Life Science and Technology, Kunming University of Science and Technology.

Extraction and segmentation of $S$. przewalskii: $S$. przewalskii was grounded to 60 mesh. The $7 \mathrm{~kg}$ ground sample was extracted with $25 \mathrm{~L}$ acetone by ultrasonic extraction technology for 3 times ( $1 \mathrm{~h}$ each time). After filtration, the acetone extract $(300 \mathrm{~g})$ was obtained by in vacuo concentration at $50^{\circ} \mathrm{C}$. The acetone extract ( $300 \mathrm{~g}$ ) was chromatographed over a silica gel (80-100 mesh) (Qing dao Hai yang Chemical Co. Ltd, P.R. China) column using a gradient of petroleum ether-ethyl acetate (from 9:1 to 3:7) and then separated into 4 fractions, Fr.1 (petroleum ether : ethyl acetate $=9: 1,80$ g), Fr.2 (petroleum ether : ethyl acetate $=3: 1,52 \mathrm{~g}$ ), Fr.3 (petroleum ether : ethyl acetate $=1: 1,45 \mathrm{~g}$ ), Fr.4 (petroleum ether:ethyl acetate $=3: 7,106 \mathrm{~g}$ ).

Assay of antiangiogenic activity: Antiangiogenic activity of acetone extract, Fr.1, Fr.2, Fr.3 and Fr.4 on CAM was measured as described previously ${ }^{12}$. Briefly, fertilized chicken eggs were incubated at $37^{\circ} \mathrm{C}$ for 7 days. After this incubation, a small hole was punched on the broad side of the egg and a window $(1 \mathrm{~cm} \times 1 \mathrm{~cm})$ was carefully created through the egg shell, exposing the part of the CAM that contained the central vein. Sterilized filter paper disks (6 $\mathrm{mm}$ in diameter) with acetone extract, Fr.1, Fr.2, Fr.3 and Fr.4 ( $8 \mu \mathrm{g} / \mathrm{egg})$ were placed on the CAMs, At the same time, $20 \mu \mathrm{L}$ normal saline was administered for blank control and $20 \mu \mathrm{L}$ dexamethasone was administered for positive control group, eight eggs each group. The eggs were then incubated at $37^{\circ} \mathrm{C}$ for another 2 days, Lastly, an appropriate volume of stationary liquid (methanol : acetone $=1: 1$ ) was injected into the embryo chorioallantois to fix the vessels on the CAM face and then the CAM were photographed. The areas of microvessels of CAM were quantified by image analysis program Image Pro Plus (IPP, version 5.1, Media Cybernetics) ${ }^{13}$.

Isolation and identification of the compounds: In order to ascertain the major antiangiogenic components, further separation was carried out. The Fr.3 was separated over a silica gel column (200-300 mesh) using a gradient of petroleum etherethyl acetate (from 5:1-1:2) and yielded compounds 1 (240 mg) and $\mathbf{2}(86 \mathrm{mg})$. The structures were identified as przewaquinone A $(\mathbf{1})^{14}$ and przewaquinone B $(\mathbf{2})^{15}$, respectively.

Evaluating the activity of przewaquinone $A$ and przewaquinone B: The antiangiogenic activity of przewaquinone A and $B$ was determined at the dosages of $0.2,0.4$ and $0.6 \mu \mathrm{g} /$ egg in this study following the above same method and dexamethasone was used as the positive control.

Chromatographic system: Reverse-phase HPLC was performed on the Agilent 1200 HPLC system (Agilent Technologies, Santa Clara, CA, USA) that consisted of G1311A quaternary pump, G1322A degasser, G1316A column oven,
G1329A autosampler and G1315D DAD detector. Data acquisition was performed with an $\mathrm{LC}$ workstation equipped with ChemStation B.04.01 software. In order of chromatographic separation, we accomplished on Agilent Eclips XDB-C $\mathrm{X}_{18}(4.6$ $\mathrm{mm} \times 150 \mathrm{~mm}, 5 \mu \mathrm{m})$ at $25^{\circ} \mathrm{C}$ and monitored at $270 \mathrm{~nm}$. The mobile phase consisted of a gradient of water (A) and acetonitrile (B), The flow rate was maintained at $1.0 \mathrm{~mL} \mathrm{~min}^{-1}$ and the gradient profile was as follows: $\mathrm{t}_{0-18.0 \mathrm{~min}}$ : isocratic elution with $45 \%$ of $\mathrm{B} ; \mathrm{t}_{18.0-35.0 \text { min }}$ : linear gradient from $45-62 \%$ of $\mathrm{B}$;

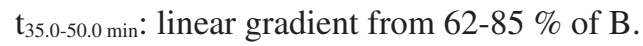

Preparation of standard solution: Stock standard solutions of przewaquinone A and B were prepared by dissolving an appropriate amount of przewaquinone $\mathrm{A}$ and $\mathrm{B}$ in methanol to give a final concentration of $2 \mathrm{mg} / \mathrm{mL}$. A serial dilution was made on each stock solution with HPLC-specific grade methanol (merck, Germany) to prepare standard solutions (przewaquinone A: 150, 300, 600, 1000, 1600 and $2000 \mu \mathrm{g} / \mathrm{mL}$; przewaquinone B: $20,50,80,100,200$ and $300 \mu \mathrm{g} / \mathrm{mL}), 10 \mu \mathrm{L}$ was used for plotting the standard curves of przewaquinone $\mathrm{A}$ and $\mathrm{B}$, respectively.

Preparation of sample solution: To prepare the sample solution, the powerd of Fr.3 was weighed initially ( $3 \mathrm{~g})$ and dissolved in $100 \% \mathrm{MeOH}$ at concentration of $3 \mathrm{mg} / \mathrm{mL}$ and filtered with $0.45 \mu \mathrm{m}$ millipore membrane filter before use.

Statistical analysis: All the tests were conducted in triplicate for determination of the antiangiogenic activities of samples. The results were recorded as mean \pm standard deviation. Differences between the experimental groups were determined by the Students's $t$-test and $p$-values less than 0.05 were considered to be significant.

\section{RESULTS AND DISCUSSION}

Screening of active site: As shown in Table-1 and Fig. 1, compared with control group the vascular area inhibition ratio of Fr.3 and Fr.4 are 68.6 and $-68.5 \%$, respectively. So Fr.3 could inhibit angiogenesis significantly, on the contrary, Fr.4 has a good proangiogenic activity. This result tells us that $S$. przewalskii can be used to develop angiogenesis inhibitors and angiogenesis accelerators.

\begin{tabular}{cccc}
\multicolumn{5}{c}{ TABLE-1 } \\
\multicolumn{4}{c}{ EFFECT ON ANGIOGENESIS OF CAM } \\
OF DIFFERENT FRACTIONS $(\mathrm{n}=8, \overline{\mathrm{x}} \pm \mathrm{s})$ \\
\hline Group & $\begin{array}{c}\text { Concentration } \\
(\mu \mathrm{g} / \mathrm{egg})\end{array}$ & $\begin{array}{c}\text { Vascular area } \\
\text { date }(\mathrm{dots})\end{array}$ & $\begin{array}{c}\text { Inhibition } \\
\text { ratio }(\%)\end{array}$ \\
\hline Acetone extract & 8 & $250 \pm 40$ & 10.7 \\
Fr.1 & 8 & $110 \pm 42^{* * *}$ & 60.7 \\
Fr.2 & 8 & $160 \pm 64^{* * *}$ & 42.8 \\
Fr.3 & 8 & $88 \pm 33^{* * *}$ & 68.6 \\
Fr.4 & 8 & $472 \pm 61$ & -68.5 \\
Dex & - & $79 \pm 28^{* * *}$ & 71.7 \\
Control & - & 280 & - \\
\hline Note: Compare with control, ${ }^{* * *} p<0.001$. &
\end{tabular}

Identification of the compounds: The structures of compounds $\mathbf{1}$ and $\mathbf{2}$ were analyzed in Bruker AM-400 spectrometer (Germany). compounds $\mathbf{1}$ and $\mathbf{2}$ were identified as przewaquinone $\mathrm{A}(\mathbf{1})$ and przewaquinone B (2) finally, the ${ }^{1} \mathrm{H}$ and ${ }^{13} \mathrm{C}$ NMR of przewaquinone $\mathrm{A}$ (1) and przewaquinone $\mathrm{B}$ (2) as described below and the structures shown in Fig. 2. 


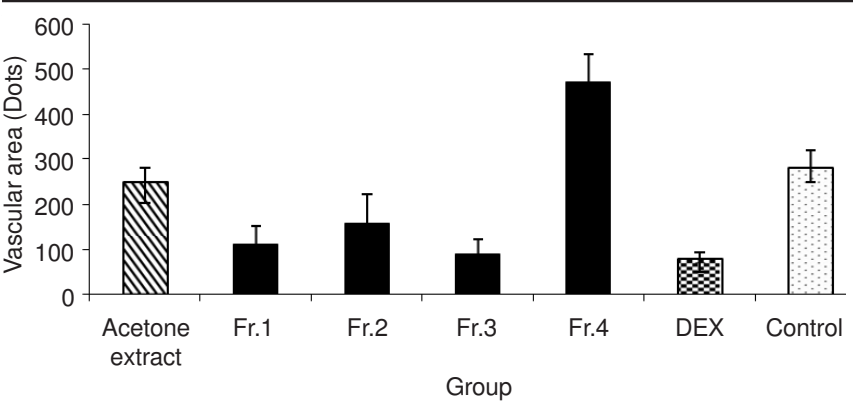

Fig. 1. Vascular area date of CAM with different fractions

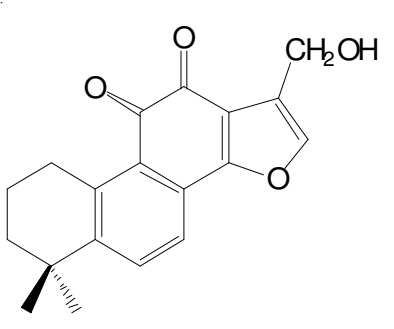

1

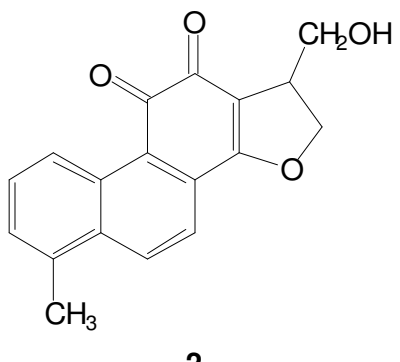

2
Fig. 2. Structures of compounds $\mathbf{1}$ and $\mathbf{2}$

Przewaquinone A (1): Red powder, m.p. 171-173 ${ }^{\circ} \mathrm{C}$, ESI-MS m/z: $311[\mathrm{M}+\mathrm{H}]^{+} .{ }^{1} \mathrm{H}$ NMR (400 MHz, $\left.\mathrm{CD}_{3} \mathrm{OD}\right) \delta$ : $3.30(2 \mathrm{H}, \mathrm{d}, J=1.45 \mathrm{~Hz}, \mathrm{H}-1), 3.09$ (2H, t, $J=6.2 \mathrm{~Hz}, \mathrm{H}-2)$, $4.68(2 \mathrm{H}, \mathrm{s}, \mathrm{H}-3), 7.73$ (1H, d, $J=8.1 \mathrm{~Hz}, \mathrm{H}-6), 7.57(1 \mathrm{H}, \mathrm{s}$, $\mathrm{H}-7), 7.51(1 \mathrm{H}, \mathrm{d}, J=8.1 \mathrm{~Hz}, \mathrm{H}-15), 1.82(2 \mathrm{H}, \mathrm{m}, J=6.0 \mathrm{~Hz}$, $\mathrm{Me}-17), 1.31$ (6H, s, Me-18 and Me-19). ${ }^{13} \mathrm{C} \mathrm{NMR}(100 \mathrm{MHz}$, $\left.\mathrm{CD}_{3} \mathrm{OD}\right) \delta$ : 31.1(C-1), 20.1 (C-2), 38.9 (C-3), 35.6 (C-4), 151.6 (C-5), 134.9 (C-6), 121.5 (C-7), 128.4 (C-8), 127.6 (C-9), 145.5 (C-10), 183.8 (C-11), 176.2 (C-12), 127.4 (C-13), 163.6 (C-14), 143.3 (C-15), 119.4 (C-16), 56.0 (C-17), 32.1 (C-18 and C-19).

Przewaquinone B (2): Brown powder, m.p. $240-242^{\circ} \mathrm{C}$, ESI-MS m/z: $293[\mathrm{M}+\mathrm{H}]^{+} .{ }^{1} \mathrm{H}$ NMR $\left(400 \mathrm{MHz}, \mathrm{C}_{5} \mathrm{D}_{5} \mathrm{~N}\right) \delta$ : $9.57(1 \mathrm{H}, \mathrm{d}, J=8.0 \mathrm{~Hz}, \mathrm{H}-1), 7.75(1 \mathrm{H}, \mathrm{d}, J=8.8 \mathrm{~Hz}, \mathrm{H}-2)$, $7.49(1 \mathrm{H}, \mathrm{d}, J=6.8 \mathrm{~Hz}, \mathrm{H}-3), 8.25(1 \mathrm{H}, \mathrm{d}, J=8.4 \mathrm{~Hz}, \mathrm{H}-6)$, 7.99 (1H, d, J=8.8 Hz, H-7), 7.25 (1H, s, H-16), 5.21 (3H, s, Me-17), 2.51 (3H, s, Me-18). ${ }^{13} \mathrm{C}$ NMR (100 MHz, $\left.\mathrm{C}_{5} \mathrm{D}_{5} \mathrm{~N}\right) \delta$ : 128.4 (C-1), 132.5 (C-2), 130.3 (C-3), 133.7 (C-4), 132.8 (C-5), 130.3 (C-6), 118.9 (C-7), 128.8 (C-8), 123.7 (C-9), 129.4 (C-10), 182.9 (C-11), 175.3 (C-12), 119.6 (C-13), 160.9 (C-14), 124.8 (C-15), 142.6 (C-16), 55.7 (C-17), 19.4 (C-18).

Effect of przewaquinone $A$ and przewaquinone $B$ on CAM: The antiangiogenic activity of przewaquinone A and $\mathrm{B}$ were also evaluated by the CAM model, which provides a unique model for investigating the effect of anti-angiogenic agents on the process of new blood vessel formation ${ }^{16}$. As shown in Table-2, Figs. 3 and 4, przewaquinone A showed a notable restraint at the dose of $4 \mu \mathrm{g} / \mathrm{egg}$, the inhibition ratio is $72.2 \%$ and the most interesting thing is that the antiangiogenic activity of przewaquinone $\mathrm{A}$ is higher than that of positive control at the dose of $6 \mu \mathrm{g} / \mathrm{egg}$, the inhibition ratio is $73.5 \%$. Meanwhile, we can find przewaquinone B could also inhibit angiogenesis significantly at the dose of $6 \mu \mathrm{g} / \mathrm{egg}$ incubation, the inhibition ratio of this dose is $70.2 \%$. These finding suggested that przewaquinone $\mathrm{A}$ and przewaquinone B might be promising candidates for angiogenesis inhibitors.

\begin{tabular}{cccc}
\hline \multicolumn{5}{c}{ TABLE-2 } \\
\multicolumn{5}{c}{ EFFECT ON ANGIOGENESIS OF CAM } \\
OF PRZEWAQUINONE A AND B $(\mathrm{n}=8, \quad \overline{\mathrm{x}} \pm \mathrm{s})$ \\
\hline \multirow{2}{*}{ Group } & $\begin{array}{c}\text { Concentration } \\
(\mu \mathrm{g} / \mathrm{egg})\end{array}$ & $\begin{array}{c}\text { Vascular area } \\
\text { date }(\mathrm{dots})\end{array}$ & $\begin{array}{c}\text { Inhibition ratio } \\
(\%)\end{array}$ \\
& 2 & $396 \pm 80$ & 0.0 \\
\multirow{2}{*}{ Przewaquinone } & 4 & $109 \pm 64^{* * *}$ & 72.2 \\
$\mathrm{~A}$ & 6 & $106 \pm 56^{* * *}$ & 73.5 \\
\hline \multirow{2}{*}{ Przewaquinone } & 2 & $387 \pm 110$ & 3.9 \\
$\mathrm{~B}$ & 4 & $211 \pm 98^{* * *}$ & 47.6 \\
& 6 & $120 \pm 65^{* * *}$ & 70.2 \\
\hline DEX & - & $110 \pm 34^{* * *}$ & 72.5 \\
\hline Control & - & $400 \pm 76$ & - \\
\hline Note: Compare with control, ${ }^{* * *} p<0.001$. &
\end{tabular}

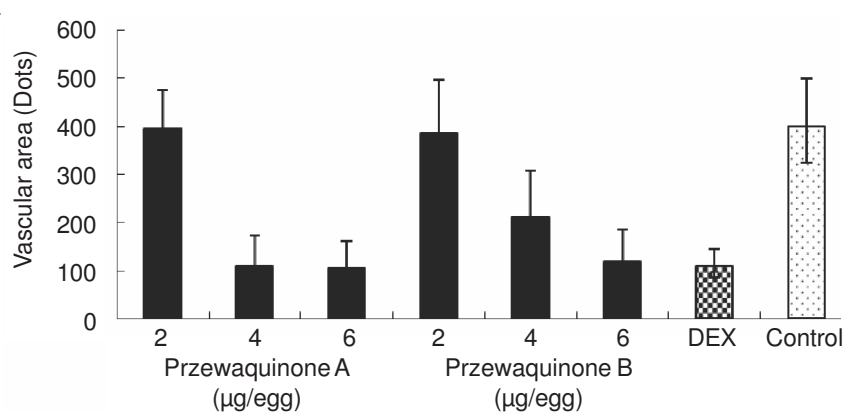

Fig. 3. Vascular area date of CAM with przewaquinone A and przewaquinone $\mathrm{B}$

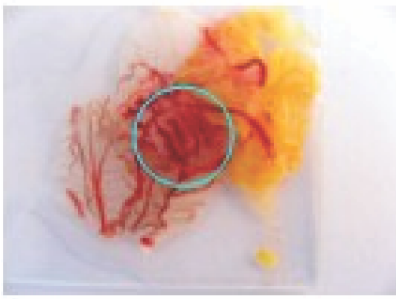

Normal saline

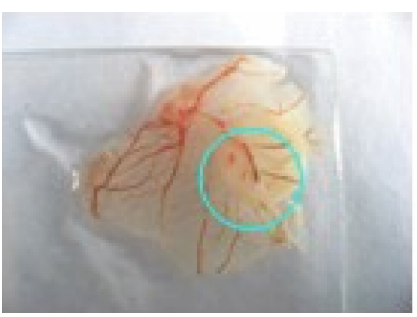

Przewaquinone A

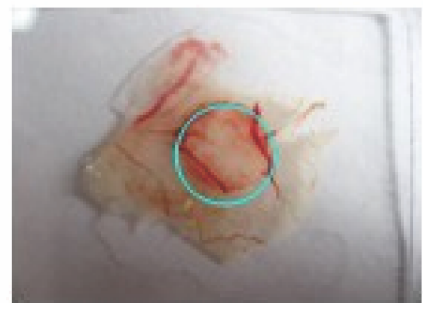

Dexamethasone

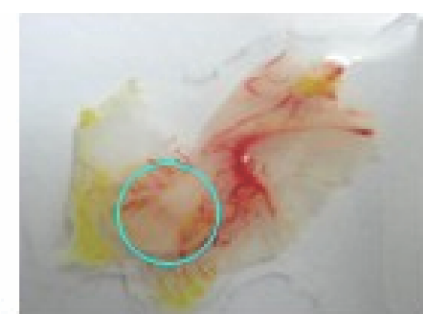

Przewaquinone B
Fig. 4. Picture specimens of CAM with przewaquinone A and przewaquinone B

Quantitative analysis of przewaquinone A andprzewaquinone B from Fr.3

Linearity, limits of quantification and detection: $\mathrm{Six}$ concentrations of the analytes' solution (przewaquinone A: 150 , $300,600,1000,1600$ and $2000 \mu \mathrm{g} / \mathrm{mL}$; przewaquinone B: 20 , $50,80,100,200$ and $300 \mu \mathrm{g} / \mathrm{mL}$ ) were used to determine linear range of the analytes, The results of calibration were summarized in Table-3 and good correlations were found between the peak area (y) and concentration of tested compounds ( $x)(r>0.9995)$ within test ranges. The limit of detection (LOD) and quantification (LOQ) under the present chromatographic conditions were determined at signal-to-noise ratios 
TABLE-3

CALIBRATION CURVES, LOD AND LOQ FOR PRZEWAQUINONE A AND PRZEWAQUINONE B

\begin{tabular}{cccccc}
\hline Analyte & Calibration curves & Correlation coefficient $(\mathrm{r})$ & Linear range $(\mu \mathrm{g} / \mathrm{mL})$ & $\mathrm{LOD}(\mu \mathrm{g} / \mathrm{mL})$ & $\mathrm{LOQ}(\mu \mathrm{g} / \mathrm{mL})$ \\
\hline Przewaquinone A & $\mathrm{y}=40.727 \mathrm{x}+49.243$ & 0.9999 & $150-2000$ & 0.05 & 0.20 \\
Przewaquinone B & $\mathrm{y}=19.967 \mathrm{x}+59.955$ & 0.9999 & $20-300$ & 0.05 & 0.20 \\
\hline
\end{tabular}

$(\mathrm{S} / \mathrm{N})$ of 3 and 10, respectively. The results showed in Table-3 clearly indicated that the analytical method was acceptable with excellent sensitivity.

Precision and accuracy: Dilute the stock solutions of przewaquinone $\mathrm{A}$ and przewaquinone $\mathrm{B}$ to concentration of 600 and $80 \mu \mathrm{g} / \mathrm{mL}$, respectively. The precision was evaluated using measurements of the repeatability (intra-day) and intermediate precision (inter-day). The intra-day precisions of the proposed method were validated with standard solution of przewaquinone $\mathrm{A}$ and przewaquinone $\mathrm{B}$ at the concentrations of 600 and $80 \mu \mathrm{g} / \mathrm{mL}$ on 1 day $(\mathrm{n}=5)$ and the inter-day precisions of the proposed method were validated with standard solution of przewaquinone $\mathrm{A}$ and przewaquinone $\mathrm{B}$ at the concentrations of 600 and $80 \mu \mathrm{g} / \mathrm{mL}$ on three consecutive days (two times a day). The calculated RSD and accuracy are summarized in Table-4. As can be seen, the assay precision ranged from 0.15 $0.31 \%$ and the accuracy was in the range of $98.81-101.32 \%$.
Recovery study: In order to validate the accuracy of the method, a known amount (low, medium and high levels) of the two standard chemicals (przewaquinone $\mathrm{A}$ and przewaquinone B) were added into samples (Fr.3) with known (1144.74 and $285.19 \mu \mathrm{g} / \mathrm{mL}$ ) przewaquinone A and przewaquinone B content, the recovery rate of the method was determined at the reaction conditions used and the results are shown in Table-5. As can be seen, the RSDs were in the range of 1.08-1.21\% and the recoveries of analytes varied from $95.34-98.02 \%$. The results indicated that the developed method showed the reliability and accuracy for the measurement of these constituen.

Przewaquinone $A$ and przewaquinone $B$ contents of Fr.3: Under the chromatographic condition described above, a sufficiently large number of peaks on the chromatogram (Fig. 5) were achieved within $50 \mathrm{~min}$ and can baseline separate all compounds. The peak identification of reference compounds was based on the retention time and the UV spectra against
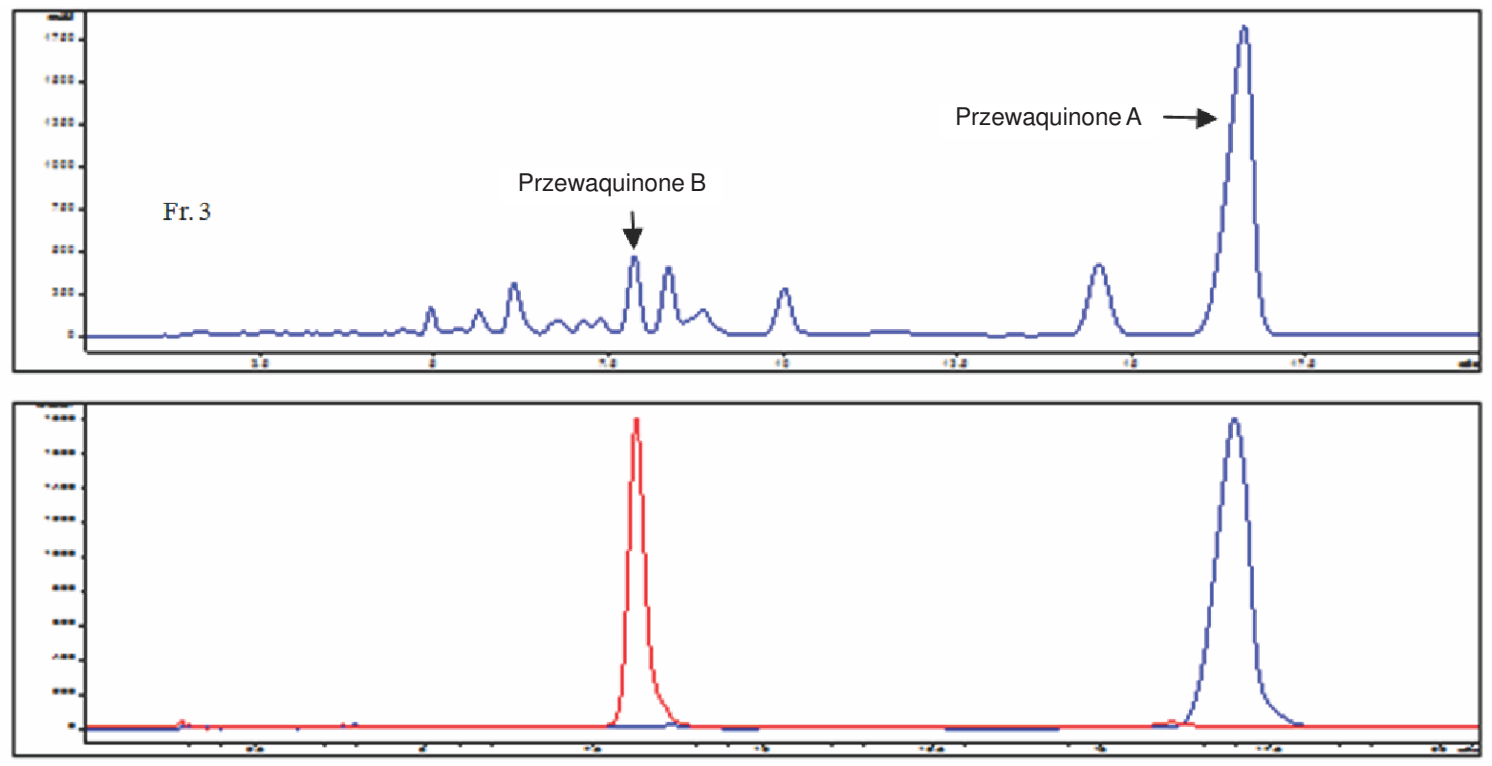

Fig. 5. Chromatograms of Fr.3, przewaquinone A and przewaquinone B

\begin{tabular}{cccccccc}
\multicolumn{7}{c}{ TABLE-4 } \\
\cline { 3 - 8 } Analyte & $\begin{array}{c}\text { Contents } \\
\text { INTRA- AND INTER-DAY PRECISION AND ACCURACY }\end{array}$ & \multicolumn{3}{c}{ Intra-day precisions $(\mathrm{n}=5)$} & \multicolumn{4}{c}{ Inter-day precisions $(\mathrm{n}=6)$} \\
\cline { 3 - 9 } & $(\mu \mathrm{g} / \mathrm{mL})$ & Detected $(\mu \mathrm{g} / \mathrm{mL})$ & Recovery rate $(\%)$ & RSD $(\%)$ & Detected $(\mu \mathrm{g} / \mathrm{mL})$ & Recovery rate $(\%)$ & $\mathrm{RSD}(\%)$ \\
\hline Przewaquinone A & 600.0 & 593.22 & 98.87 & 0.25 & 592.86 & 98.81 & 0.31 \\
Przewaquinone B & 80.0 & 81.056 & 101.32 & 0.17 & 80.992 & 101.24 & 0.15 \\
\hline
\end{tabular}

\begin{tabular}{|c|c|c|c|c|c|c|}
\hline \multicolumn{7}{|c|}{$\begin{array}{c}\text { TABLE-5 } \\
\text { RECOVERY RATES }(n=3)\end{array}$} \\
\hline Analyte & Background $(\mu \mathrm{g} / \mathrm{mL})$ & Added $(\mu \mathrm{g} / \mathrm{mL})$ & Detected $(\mu \mathrm{g} / \mathrm{mL})$ & Recovery rate $(\%)$ & Average recovery rate $(\%)$ & $\operatorname{RSD}(\%)$ \\
\hline \multirow{3}{*}{ Przewaquinone A } & \multirow{3}{*}{1144.74} & 150 & 1263.28 & 97.57 & \multirow{3}{*}{96.18} & \multirow{3}{*}{1.21} \\
\hline & & 300 & 1377.42 & 95.34 & & \\
\hline & & 600 & 1668.49 & 95.63 & & \\
\hline \multirow{3}{*}{ Przewaquinone B } & \multirow{3}{*}{285.19} & 20 & 299.14 & 98.02 & \multirow{3}{*}{96.90} & \multirow{3}{*}{1.08} \\
\hline & & 50 & 321.31 & 95.86 & & \\
\hline & & 100 & 372.98 & 96.83 & & \\
\hline
\end{tabular}


the standards presented in the chromatogram. The relative quantity of przewaquinone $\mathrm{A}$ and przewaquinone $\mathrm{B}$ in Fr.3 was calculated from each equation, the result is that the przewaquinone A and przewaquinone B contents in Fr.3 were 38.16 and $9.51 \%$, respectively.

\section{Conclusion}

In this research, the active site (Fr.3) and active compounds (przewaquinone A, przewaquinone B) which have anti-angiogenic activity have been obtained from $S$. przewalskii rapidly by activity-oriented separation method. The most exciting is that przewaquinone $\mathrm{A}$ and $\mathrm{B}$ were found have anti-angiogenic activity for the frist time. These finding suggested that przewaquinone $\mathrm{A}$ and $\mathrm{B}$ might be promising candidates for angiogenesis inhibitors. At the same time, a good pro-angiogenic active site (Fr.4) also been found from S. przewalskii, this result indicate that $S$. przewalskii can also be used to develop angiogenesis accelerator. In addition, quantitative analysis of przewaquinone $\mathrm{A}$ and $\mathrm{B}$ in active site (Fr.3) was carried out and the contents of them in Fr.3 were 38.16 and $9.51 \%$ respectively. Combined with the results of pharmacological experiments, we can reasonably inferred that the important reason lead to Fr.3 show a good anti-angiogenic activity is due to the presence of a large number of przewaquinone A and B, Further demonstrate that the activity-oriented separation method is efficient and accurate. So it is important to research the active compounds of $S$. przewalskii.

\section{ACKNOWLEDGEMENTS}

This work was supported by the National Natural Science Foundation of China (No. 30960042).

\section{REFERENCES}

1. L. Bo, N.F. Di, L.Z. Wen, Z.H. Jie, W.D. Zu and S.H. Dong, Phytochemistry, 30, 3815 (1991).

2. A. Matkowski, S. Zielinska, J. Oszmianski and E.L. Zarawska, Bioresour. Technol., 99, 7892 (2008).

3. W.S. Chen, X.M. Jia, W.D. Zhang, Z.Y. Lou and C.Z. Qiao, Yaoxue Хuebao, 38, 354 (2003).

4. N. Wang, M. Niwa and H.W. Luo, Phytochemistry, 27, 299 (1988).

5. W. Zhijun, O. Mingan and Y. Chongren, Acta Botanica Yunnanica, 21, 512 (1999).

6. P. Carmeliet, Nature, 438, 932 (2005).

7. P. Nyberg, L. Xie and R. Kalluri, Cancer Res., 65, 3967 (2005).

8. J. Folkman, Ann. Surgery, 175, 409 (1972).

9. J. Folkman, Eur. J. Cancer, 32, 2534 (1996).

10. L.J. Yang, C.J. Jeng, H.N. Kung, C.C. Chang, A.G. Wang, G.Y. Chau, M.J. Don and Y.P. Chau, J. Biomed. Sci., 12, 347 (2005).

11. J.M. Hur, J.S. Shim, H.J. Jung and H.J. Kwon, Exp. Mol. Med., 37, 133 (2005).

12. N. Lu, Y. Yang, Q.D. You, Y. Ling, Y. Gao, H.Y. Gu, L. Zhao, X.T. Wang and Q.L. Guo, Cancer Lett., 258, 80 (2007).

13. A. Hayek, G.M. Beattie, A.D. Lopez and P. Chen, Microvascular Res., 41, 203 (1991).

14. H.W. Luo, M.Y. Wu, Z.G. Yong, M. Niwa and Y. Hirata, Phytochemistry, 24, 815 (1985).

15. B.J. Yang, M.K. Qian, G.W. Qin and Z.X. Chen, Acta Pharm. Sin., 16, 837 (1981).

16. Y. Chen, N. Lu, Y. Ling, L. Wang, Q. You, Z. Li and Q. Guo, J. Pharmacol. Sci., 112, 37 (2010). 